\title{
Gigantic Capacito-Energetic Parameters of Lithium-Intercalation Current Generation Reaction in Nanodispersed $\mathrm{TiO}_{2}$ with Defective Structure
}

\author{
I. Grygorchak ${ }^{a, *}$, I. MyronyuK ${ }^{b}$, M. Micov $^{a}$, A. Pidluzhna ${ }^{a}$ And O. OstapuK ${ }^{a}$ \\ ${ }^{a}$ Lviv Polytechnic National University, 1 Kotlyarevsky St., 79013 Lviv, Ukraine \\ ${ }^{b}$ Precarpathian University, 57 Shevchenko St., 76000 Ivano-Frankivsk, Ukraine
}

\begin{abstract}
To determine the reasons of the difference between the parameters of lithium intercalation process for materials of the same nature, the nanodispersed $\mathrm{TiO}_{2}$ was synthesized by pyrogenic method from $\mathrm{TiCl}_{4}$ in hydrogen-air flame with $\mathrm{SiCl}_{4}$ doping precursor and was compared with $\mathrm{TiO}_{2}$ of "Merck" quality. The X-ray analysis with the use of small-angle scattering method, electronic scanning microscopy and impedance spectroscopy were used to determine aforesaid parameters. Obtained results show that the reason of such behaviour lays in size effect and in modification of energetic topology of impurity system. Thermodynamic parameters of intercalation reaction agree well with investigated properties of ceramic samples.
\end{abstract}

PACS numbers: 71.55.Jv

\section{Introduction}

Nowadays, the problem of increasing power generation per unit mass and unit volume of a power source active substance is of paramount importance. The transition to nanosize of particles of cathode active material, which participate in $\mathrm{Li}^{+}$-intercalation current generating reaction, is one of the most effective methods to solve this problem $[1,2]$.

The cause of the improvement of aforesaid parameters for non-metallic nanocrystal phases can be well interpreted by the concept of "electrochemical grafting" $[2,3]$. It consists in the fact that during the transition to nanocrystal state the relative density of states increases in the gap. As to their origin, these states are superficial ones. The following equation can help to understand the process $[4,5]$ :

$$
\Delta G(x)=e E(x)=\mu_{\mathrm{i}}(x)-\mu_{0},
$$

where $\Delta G(x)$ is the change of the Gibbs energy of the reaction, $e$ is the charge of electron, $E$ is the electromotive force of the reaction, $\mu_{\mathrm{i}}(x)$ is the chemical potential of the lithium insertion into the host structure, $\mu_{0}$ is the chemical potential of lithium in the metallic lithium anode, $x$ is the number of lithium atoms per unit of the host material according to the formula. From the point of view of the thermodynamics of the $\mathrm{Li}^{+}$-intercalation current generation and according to Eq. (1), such transition means a change in the behaviour of $\mu_{\mathrm{i}}(x)$. Its dependence on the degree of guest load $x$ can be represented by the equation [6]:

* corresponding author; e-mail: ivangr@rambler.ru

$$
\begin{aligned}
& \mu_{\mathrm{i}}(x)=k T \ln |x /(1-x)|+Z \omega x+\left[E_{\mathrm{F}}(x)-E_{\mathrm{F}}(0)\right] \\
& \quad+L \partial C / \partial x+E_{0} .
\end{aligned}
$$

Here $k$ is the Boltzmann constant, $Z$ is the number of the nearest neighbouring places, $\omega$ is the energy of interaction of inserted guest components, $E_{\mathrm{F}}$ is the position of the Fermi level, $C$ is the distance between the layers, $\mathrm{L}$ is the coefficient which is determined by the Lennard-Jones potential function, $E_{0}$ is the bonding energy between intercalated atoms and matrix layers. It is evident that the change in $\mu_{\mathrm{i}}(x)$ causes a change in the structure of the discharge curve. At initial stages of intercalation, the first and the fourth terms of Eq. (2) essentially influence $\mu_{\mathrm{i}}(x)$. The bonding energy $E_{0}$ provided is independent of $x$ and constant. The discharge curve is formed by concentrational dependences of interaction energy in the subsystem of intercalant and by those of the change of the Fermi level position. The character of the latter factor is determined by the energetic topology of the system of host material defects. This system of defects is conditioned not only by nanosizes but by their own defects caused by growth or doping. This energetic topology of the system of host material defects determines the position of $E_{0}$ and non-directly influences $E(x)$. It is clear that aforesaid factors are closely related to the technology of obtaining nanodispersed forms.

The second problem is the catastrophic depletion of raw materials resources for traditional cathode-active materials [7] and their harmful influence on the environment. Titanium dioxide is a prospective material from this standpoint. Long before it was known $[8,9]$ that it could serve as a topochemico-reversible electrode material in $\mathrm{Li}^{+}$-ion accumulators reaching its maximal degree 
of guest load $x=1$ at a discharge down to $1 \mathrm{~V}$. However, the magnitude of specific capacity which is ensured by this macrostructural $\mathrm{TiO}_{2}$ powder can not be considered satisfactorily any more. However, the transition to nanosized state has given a possibility to apply $\mathrm{TiO}_{2}$ as an anode for lithium-intercalation current-generation [10]. In this case, the value of reversible capacity of $150 \mathrm{mAh} / \mathrm{g}$ is reached.

Analysis of the results obtained from investigations of lithium-intercalation processes in nanodispersed forms of titanium dioxide shows that the specific capacity (when discharging to a voltage down to $1 \mathrm{~V}$ ) strongly depends on the methods of synthesis of nanodispersed forms, and it can vary from $335 \mathrm{mAh} / \mathrm{g}$ [11] to $600 \mathrm{mAh} / \mathrm{g}[12,13]$. If the proportion of the mixed anatase-rutile phases and the magnitude of active surface area remain the same, but the conditions of the synthesis or annealing temperatures differ, the specific capacity may differ more than twice [14].

However, the problem of the possibility of ensuring essential increase of specific capacity in cathode process remains unsolved yet. Therefore, the aim of this work is an attempt to solve this problem.

\section{Conceptual bases and technique of experiment}

The solution of the set problem with taking into account the necessity of ensuring a high concentration of guest positions should be searched in the choice of such technique of synthesis which could enable us to control defects caused by growth (they can become additional guest positions as well) and impurity subsystem, with the necessary topology of energy levels in the gap.

Therefore, in order to ensure the realization of the first of these conditions, for obtaining nanodispersed $\mathrm{TiO}_{2}$ just pyrogenic method was chosen, which was carried out by means of burning of $\mathrm{TiCl}_{4}$ in a hydrogen-air flame at temperature of $980^{\circ} \mathrm{C}$. This ensured the value of specific surface $\approx 103 \mathrm{~m}^{2} / \mathrm{g}$.

According to the second condition, the element of the IVth group - silicon, which is a constituent part of $\mathrm{SiCl}_{4}$ precursor, was chosen as a dopant on the basis of previous results of investigations [15]. All the chemical reagents used in the experiments were analytical grade without further purification. To compare the properties of synthesized material, the titanium dioxide $\mathrm{TiO}_{2}-\mathrm{M}$ of "Merck" quality was chosen.

$\mathrm{X}$-ray investigations of the structure of the obtained product were carried out by DRON-3 diffractometer in $\mathrm{CuK}_{\alpha}$ radiation $(\lambda=1.5418 \AA)$. The size of sedimented fractions was determined by both - the low angle X-ray dispersion [16] and by electronic microscopy.

The elemental analysis of investigated materials has been carried out with OXFORD INCA Energy350 spectrometer on the basis of JSM-6490LV electronic scanning microscope made by JEOL firm (i.e., perfectly focusing spectrometer with the Rouland round of $210 \mathrm{~mm}$ and the angle range from $330^{\circ}$ to $135^{\circ}$ ).
For electrochemical investigations, electrodes with the area of $0.5 \mathrm{~cm}^{2}$ on $\mathrm{Ni}$ substrate were formed. The electrode consisted of titanium dioxide powder, acetylene black as a conductive admixture and the binding agent, in the mass proportion of $85 \%: 10 \%: 5 \%$. The mass of nanodispersed titanium dioxide did not exceed $3 \mathrm{mg}$. Thermodynamic electrochemical laws of lithium intercalation have been investigated in a three-electrode cell with one-mole solution of $\mathrm{LiBF}_{4}$ in $\gamma$-butyrolactone, a lithium electrode, and a silver chloride reference electrode. The method of impedance spectroscopy in a frequency range of $10^{-3}-10^{5} \mathrm{~Hz}$ with a help of "AUTOLAB" measuring equipment of "ECO Chemie" firm (the Netherlands) equipped with FRA and GPES software was used.

\section{Results and discussion}

The results of X-ray investigation of the structure of the obtained $\mathrm{TiO}_{2}-\mathrm{N}$ product and titanium dioxide $\mathrm{TiO}_{2}-\mathrm{M}$ of "Merck" quality are illustrated in Fig. 1. The phase analysis of the $\mathrm{TiO}_{2}-\mathrm{M}$ sample refers it to anatase modification. Besides, weak diffractional maxima of an unidentified phase (volumetric content $\approx 9 \%$ ) were observed. The phase analysis of the $\mathrm{TiO}_{2}-\mathrm{N}$ sample has indicated the presence of diffractional maxima of anatase-rutile mixture with the proportion of $81 \%: 19 \%$, and the presence of diffraction lines of the unidentified phase at X-ray background level. The increased half-width of the diffraction lines shows that the synthesized titanium dioxide, according to our aim, contains more defects of structure. From Fig. 2 it also follows that the obtained nanodispersed $\mathrm{TiO}_{2}-\mathrm{N}$ particles essentially differ from $\mathrm{TiO}_{2}-\mathrm{M}$ in regard to their morphology.

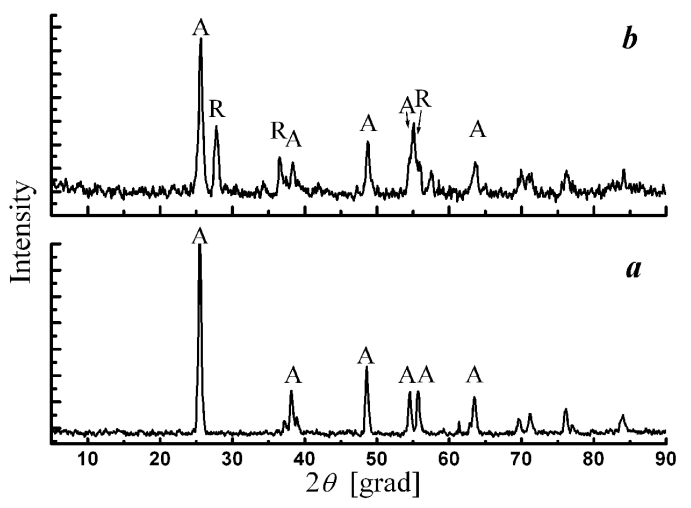

Fig. 1. X-ray diffractogram of nanodispersed $\mathrm{TiO}_{2}-\mathrm{M}$ (a) and $\mathrm{TiO}_{2}-\mathrm{N}(\mathrm{b})(\mathrm{A}$ - anatase, $\mathrm{R}$ - rutile).

Obtained results of elemental analysis indicate that, as to its chemical composition, titanium dioxide of "Merck" trade mark contains no impurity. But, the synthesized $\mathrm{TiO}_{2}-\mathrm{N}$ contains impurities of silicon and chlorine (0.3 at. \%).

In order to ascertain the influence of defecto-morphological differences of both kinds of materials on 

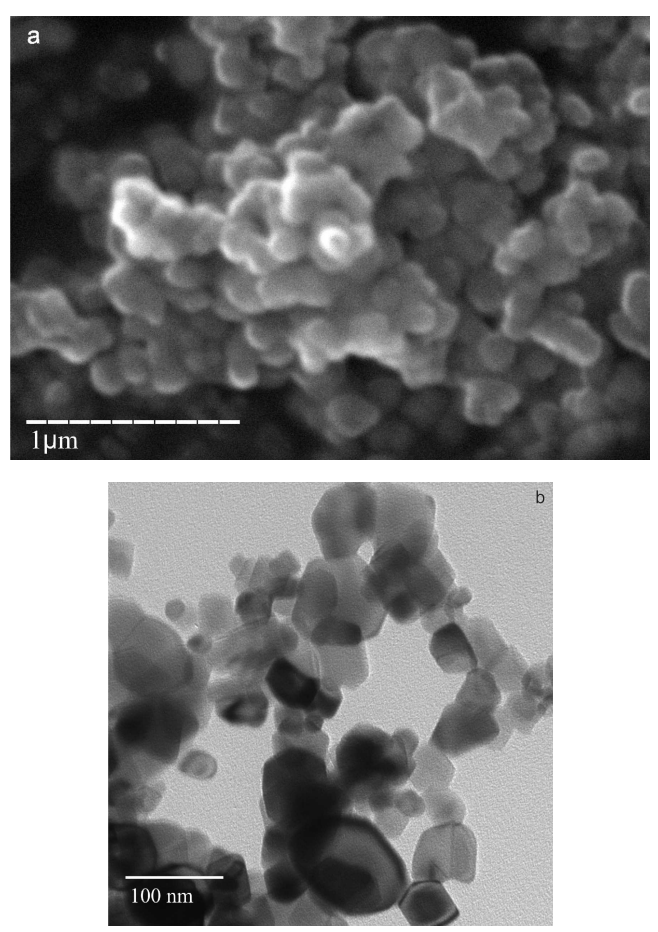

Fig. 2. SEM images of nanodispersed $\mathrm{TiO}_{2}-\mathrm{M}(\mathrm{a})$ and $\mathrm{TiO}_{2}-\mathrm{N}(\mathrm{b})$.

the energetic structure of states of the defects (which determine their kinetic and polarizational properties), investigations of temperature dependent (in the range of functionization of lithium current sources: 243-323 K) impedance of $\mathrm{TiO}_{2}-\mathrm{M}$ and $\mathrm{TiO}_{2}-\mathrm{N}$ ceramics were carried out. In Fig. 3, frequential dependences of specific resistance $\rho(x)$ of the investigated ceramics, at temperature of $293 \mathrm{~K}$ in $10^{-3}-10^{6} \mathrm{~Hz}$ frequency range, are given. It can be seen that for both materials the presence of practically low/middle frequency independent and that of high frequency decay branches is characteristic. However, for $\mathrm{TiO}_{2}-\mathrm{N}$, the first of them corresponds to higher magnitudes of specific resistances, and the beginning of pronounced frequential dispersion is shifted to the low frequency range. In order to analyze the obtained dependences, the latter were represented in the Nyquist's coordinates $Z^{\prime}-\mathrm{i} Z^{\prime \prime}$, where $Z^{\prime}$ is the real component of the impedance, and $Z^{\prime \prime}$ is the imaginary component (Fig. 4). It can be seen that for both ceramics Nyquist diagrams, in general, are of two-arc character. Uncompleted low frequency branches represent possible processes near electrode, they also allow us to model the charge transfer through intergranular boundaries. The high-frequency branches correspond to conduction of bulk $\mathrm{TiO}_{2}$ nanoparticles. Such result provides the approximation of a simple equivalent circuit, which contains a high-frequency $R_{\mathrm{V}} C_{\mathrm{V}}$ and low-frequency $R_{\mathrm{B}} C_{\mathrm{B}}$ link, respectively (Fig. 5a). However, the fine structure of hodographs indicates essentialy greater frequency dis- persion of $\mathrm{TiO}_{2}-\mathrm{N}$ parameters, thus the corresponding $R_{\mathrm{V}} C_{\mathrm{V}}$ links can be restructurized to the form of three parallel links connected in series (Fig. 5b), each of which represents an amplitude of modulation of energy relief. It is most probable that it is caused by defects of structure and by atoms of impurity energy states of which are situated in the Fermi level neighbourhood. The reason for such assumption is that in this case, the frequency dispersion corresponds to the interval in which hopping conduction is realized on localized states near the Fermi level. The fact that the form of the dependence of the tangent of the electric loss angle of the frequency (for $\mathrm{TiO}_{2}-\mathrm{N}$, this curve contains two pronounced maxima, which correspond to different times of relaxation) is also a reason (see Fig. 6).

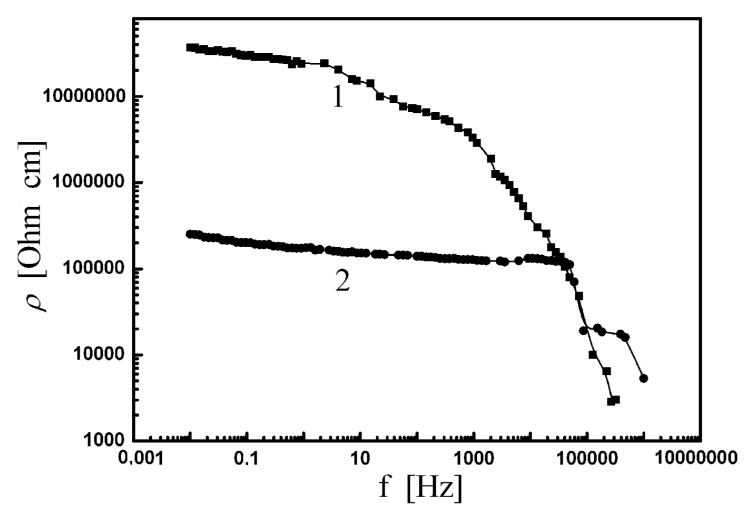

Fig. 3. Frequency dependences of specific resistance $\rho(x)$ of $\mathrm{TiO}_{2}-\mathrm{M}(1)$ and $\mathrm{TiO}_{2}-\mathrm{N}(2)$ at room temperature.

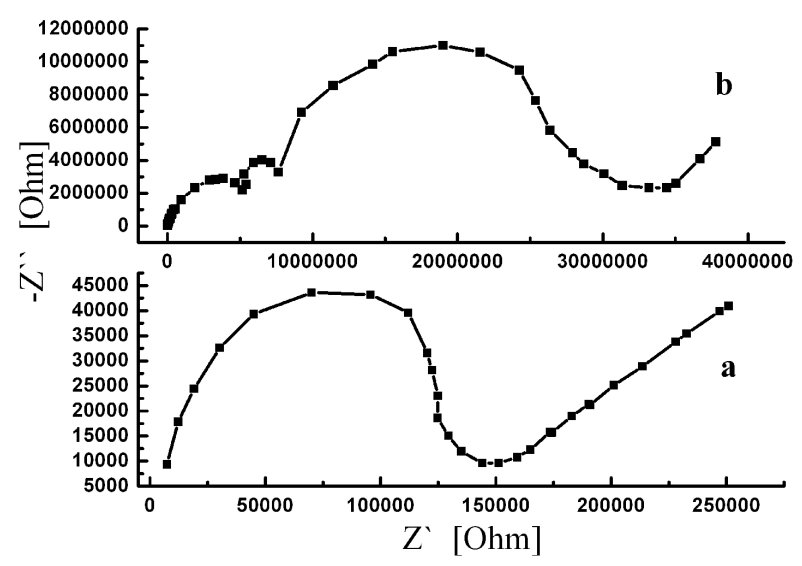

Fig. 4. Nyquist's diagrams of ceramics $\mathrm{TiO}_{2}-\mathrm{M}(\mathrm{a})$ and $\mathrm{TiO}_{2}-\mathrm{N}($ b) at room temperature.

In the frequency interval where the loss angle is less than unity, it becomes possible to correctly analyze the behavior of dielectric permittivity $\varepsilon$ as a function of frequency (Fig. 7). It is clear that for both materials, in the frequency range of $40-1000 \mathrm{kHz}$, this behavior is abnormal - it increases with the increase in frequency. 


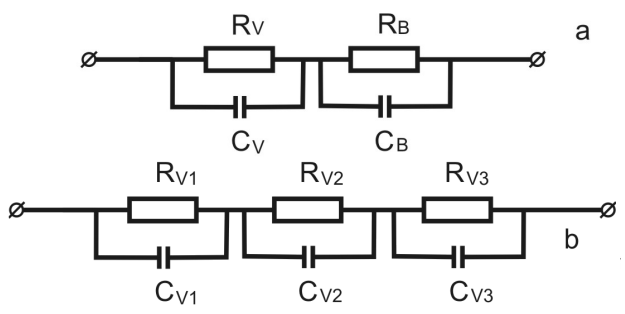

Fig. 5. Equivalent electric circuit for $\mathrm{TiO}_{2}-\mathrm{M}$ and $\mathrm{TiO}_{2}-\mathrm{N}$ without fine structure (a) and restucturized (b).

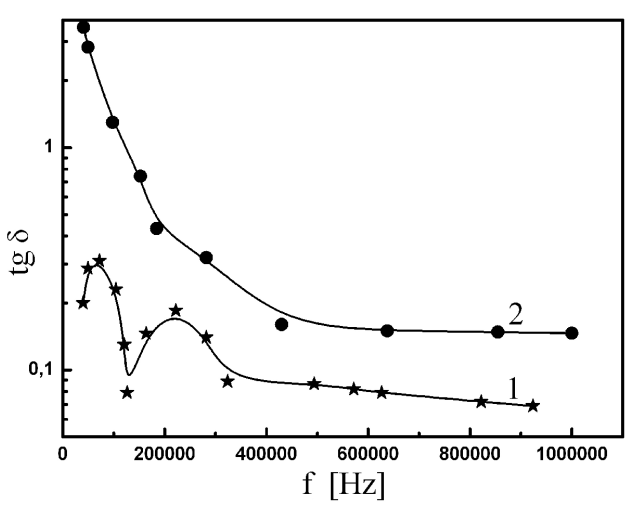

Fig. 6. Frequency dependences of $\tan \delta$ for $\mathrm{TiO}_{2}-\mathrm{N}(1)$ and $\mathrm{TiO}_{2}-\mathrm{M}(2)$ at room temperature.

According to [17], it can be assumed that the emergence of additional dipoles is related to hopping recharge of defects the energy field of which is in vicinity of the Fermi level. The essentially greater magnitude of $\varepsilon$ for $\mathrm{TiO}_{2}$, according to [18], just indicates a higher concentration of defects in it. Thus, both kinetic and polarizational characteristics unambiguously reproduce essential difference between electronic structures of $\mathrm{TiO}_{2}-\mathrm{M}$ and $\mathrm{TiO}_{2}-\mathrm{N}$

In order to ascertain the degree of correlation between

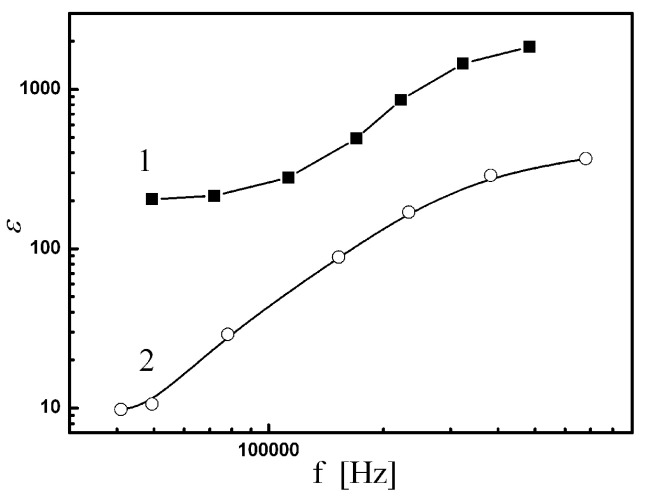

Fig. 7. Frequency dependences of dielectric permittivity $\varepsilon$ for $\mathrm{TiO}_{2}-\mathrm{N}(1)$ and $\mathrm{TiO}_{2}-\mathrm{M}(2)$ at room temperature. energy topology of impurity subsystem and the process of $\mathrm{Li}^{+}$-intercalation current generation, thermodynamical investigations according to EMF technique [19] were carried out. The results of the analysis of the behavior of Gibbs' energy change $\Delta G(x)$ and that of differential capacity $\frac{\partial x}{\partial(\Delta G(x))}$ as functions of the guest load degree for both materials are given in Fig. 8. It can be seen that the magnitude of the degree of guest load increases for $\mathrm{TiO}_{2}-\mathrm{N}$ under discharge down to the voltage of $1.6 \mathrm{~V}$, as compared to $\mathrm{TiO}_{2}-\mathrm{M}$.

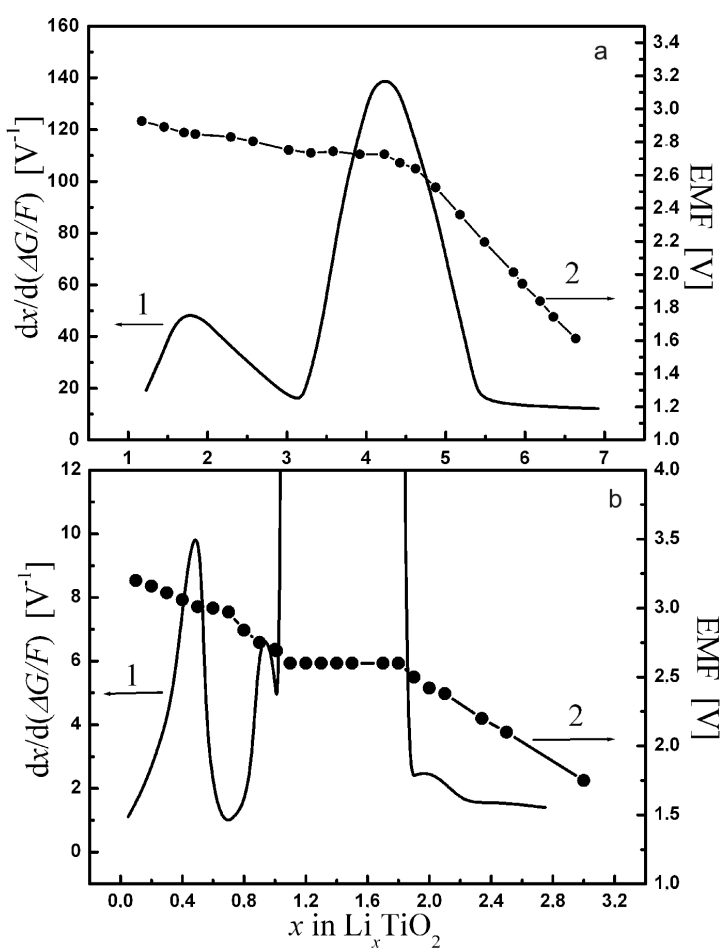

Fig. 8. Dependence of the Gibbs energy (1) and differential capacity (2) on guest load degree in $\mathrm{TiO}_{2}-\mathrm{N}(\mathrm{a})$, $\mathrm{TiO}_{2}-\mathrm{M}(\mathrm{b})$.

The sharp decrease in the Gibbs energy change of the $\mathrm{Li}^{+}$-intercalation, in concentration interval $0<x<0.6$, is caused by the entropy term and by the modification of the crystal lattice [20]. The first and the fourth terms of Eq. (2) for the chemical potential of the inserted Lithium correspond to the two aforesaid causes, respectively. With the increase in the guest load degree, the contributions from the interaction between the guest components and that from the change of Fermi level position become prevailing.

The approximative assumption that, for low magnitudes of $x(0.6<x<2.5)$ the interaction energies of guest-guest $(\omega)$ and of guest-host $\left(E_{0}\right)$ can be considered to be independent of $x$ turns out to be sufficiently substantiated. Then, the form of the $\frac{\partial(\Delta G(x) / F)}{\partial x}$ derivatives in this concentrational segment of guest load (Fig. 9) visualizes different character of the change of the Fermi level position during intercalation in the investigated ma- 


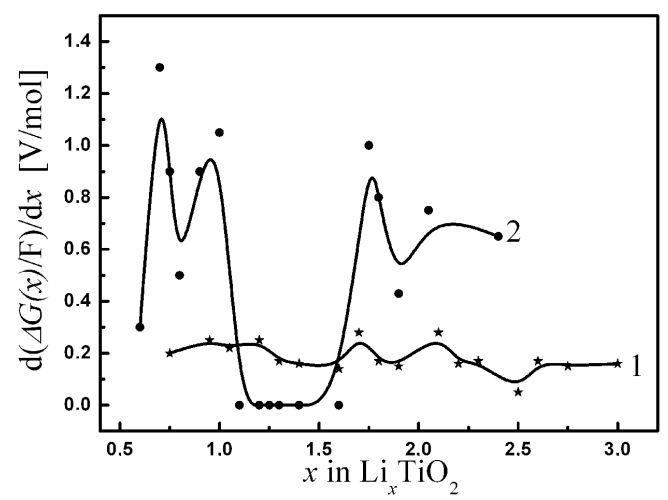

Fig. 9. Approximated character of change of the Fermi level position during intercalation process in $\mathrm{TiO}_{2}-\mathrm{M}(1)$ and $\mathrm{TiO}_{2}-\mathrm{N}(2)$.

terials, and conjugacy of the structure of the curve with them.

For $\mathrm{TiO}_{2}-\mathrm{M}$ (Fig. 8b), the curve $\Delta G(x)$ contains a plateau in the magnitude interval $1.05<x<1.8$, to which an infinite discontinuity of $\frac{\partial x}{\partial(\Delta G(x))}$ corresponds. This indicates the presence of the phase transition of the first kind with the formation of two-phase state in the given concentration interval of guest load. For $x>1.8$ the system is monophase again. Unlike for this, for $\mathrm{TiO}_{2}-\mathrm{N}$ (Fig. 8a) the process of $\mathrm{Li}^{+}$-intercalation current generation is accompanied by formation of non-stoichiometric monophase insertion $\mathrm{Li}_{x} \mathrm{TiO}_{2}$ compounds. Characteristic of them plateau of $\Delta G(x)$ in a neighbourhood of $x=1$ and in the interval $3<x<4.5$ as well as related to them maxima on $\frac{\partial x}{\partial(\Delta G(x))}$ curve indicate phase transitions, and the intervals of sharp decrease at $x \approx 3$ and $x \approx 4.5$ indicate the ordering of the subsystem of the intercalant. The form of the entropy curve on Li solution obtained independently and given in Fig. 10 can serve as a confirmation of the aforesaid.

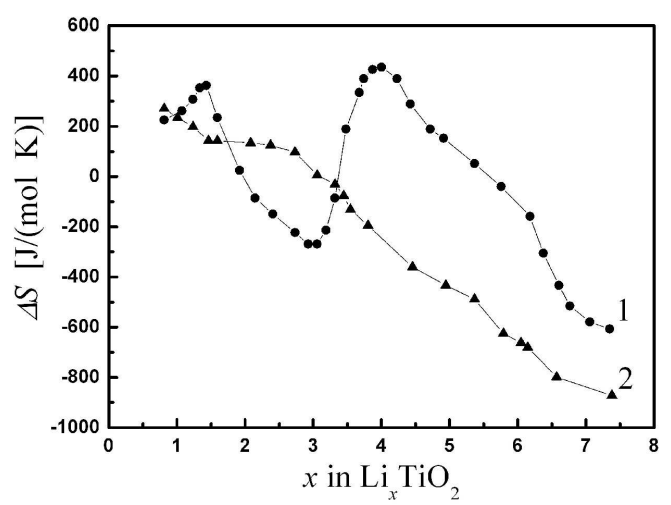

Fig. 10. Concentrational dependences of lithium solution entropy in nanosized $\mathrm{TiO}_{2}-\mathrm{M}(1)$ and $\mathrm{TiO}_{2}-\mathrm{N}(2)$.

For titanium dioxide $\mathrm{TiO}_{2}-\mathrm{M}$, the corresponding maxima in $\frac{\partial x}{\partial(\Delta G(x))}$ curve (Fig. 8b) are situated in neighbor- hoods of essentially less values $(x \approx 0.45$ and $x \approx 0.9)$. This indicates the influence of electronic structure on parameters of the formation of intercalation phases.

Analyzing the curves in Figs. $8-10$ we came to conclusion that, as it was expected, with the increase of temperature, the solution of $\mathrm{Li}$ in $\mathrm{TiO}_{2}-\mathrm{N}$ behaves more ideally. It is most probable that the nature of phase transitions in a neighbourhood of $x=1$ and in the interval $3<x<4.5$ is related to phase transitions of the second kind of "order-disorder" type. With the exception of the aforesaid concentration intervals, the entropy behaves in its usual way: it is negative and decreases to more negative magnitude with the increase in $x$ - this is caused by the decrease in the number of non-occupied guest positions. The intervals of positive magnitude of $\Delta S(x)$ are probably related to exclusively high number of degrees of freedom of oscillatory motion of $\mathrm{Li}^{+}$ions in guest canals covered with weakly polarizable oxygen anions $\mathrm{O}^{2-}$.

In Fig. 11 galvanostatic discharge curves of Lithium electrochemical cells, with cathodes on the basis of investigated materials at sufficiently high current density of $10 \mathrm{mAh} / \mathrm{g}$, are given. The obtained values of the specific capacity and the energy of $\mathrm{TiO}_{2}-\mathrm{N}$ discharge down to $1 \mathrm{~V}$ practically reach their theoretically possible maximal values per unit mass of $\mathrm{TiO}_{2}$.

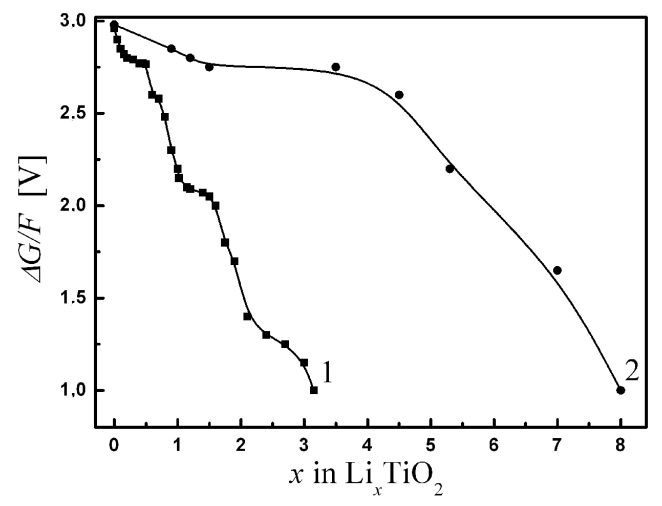

Fig. 11. Discharge curves of lithium cells with cathodes on the basis of nanodispersed $\mathrm{TiO}_{2}-\mathrm{M}$ (1) and $\mathrm{TiO}_{2}-\mathrm{N}(2)$ at current density of $10 \mathrm{~mA} / \mathrm{g}$.

\section{Conclusions}

1. Analysis of literature data and the carried out investigations unambiguously indicate that the transition from macro to nanocrystalline structure of particles generating energy in $\mathrm{Li}^{+}$-intercalation leads to pronounced increase in specific energy and power. However, just this transition alone does not ensure essential approaching of practically implemented specific capacity to the theoretically possible maximal value of corresponding cathode process. It ensures a magnitude at a level which does not exceed $1 / 3$ of the theoretically possible one, relatively to the electrochemical equivalent of lithium. We have proved that the solution of the problem of further increase in 
specific capacity for nanodispersed $\mathrm{TiO}_{2}$ can be attained through forming doping-structure defects; these defects form a certain energetic topology of electron states. And through this topology the defects formation ensures the needed dependence in the form of a function of Lithium chemical potential of guest load degree.

2. According to the aforesaid approach, the physical mechanism of essential increase in energy and specific capacity consists in such a change of the energetic topology of a defects subsystem when:

a) the density of states at Fermi level increases;

b) deep levels in gap emerge.

3. The implementation of the aforesaid conditions in practice is attained by means of the synthesis of $\mathrm{TiO}_{2}$ from $\mathrm{TiCl}_{4}$ in hydrogen-air flame at temperature of $980^{\circ} \mathrm{C}$ with $\mathrm{SiCl}_{4}$ doping precursor. As a result, titanium dioxide of mixed anatase-rutile modification $(81 \%$ and $19 \%$ ) doped with $\mathrm{Si}$ and $\mathrm{Cl}$ is obtained. Its nanoparticles are discus-shaped. The stay of coagulated fine $\mathrm{TiO}_{2}$ nanocrystals in flame for a short time, probably, cannot ensure perfect sintering and recrystallization for them, in the course of which, pores and structure defects form in their bulk. This leads to additional increase in the number of guest positions, besides their generation in the process of intercalation. As a result of this, the predicted theoretically possible maximal value of the specific capacity of the cathode process under the discharge down to the voltage of $1.0 \mathrm{~V}$, which amounted to $3400 \mathrm{mAh} / \mathrm{g}$ at a specific energy $8540 \mathrm{Wh} / \mathrm{kg}$ per unit mass of initial $\mathrm{TiO}_{2}$, is attained.

\section{References}

[1] Y. Shao-Horn, S. Osmialowski, Q.C. Horn, J. Electrochem. Soc. 149, A1499 (2002).

[2] M. Quintin, O. Devos, M.H. Delville, G. Campet, Electrochim. Acta 51, 6426 (2006).

[3] C.W. Kwon, S.J. Hwang, A. Poquet, N. Treuil, G. Campet, J. Portier, J.H. Choy, New Trends in Intercalation Compounds for Energy Storage. Series Mathematics, Physics and Chemistry 61, 439 (2002).

[4] W.R. McKinnon, R.R. Haering, Modern Aspects of Electrochemistry 15, 235 (1983).
[5] D.A. Johnson, Some Thermodynamic Aspects of Inorganic Chemistry. 2nd ed, Cambridge University Press, Cambridge, 1982.

[6] A.S. Nagelberg, W.L. Worrell, J. Solid State Chem. 38, 321 (1981).

[7] A.M. Skundin, O.N. Efimov, O.V. Yarmolenko, Russ. Chem. Rev. 71, 329 (2002).

[8] I.A. Kedrinsky, V.E. Dmitrenko, Yu.M. Povarov, I.I. Grudyanov, Chemical Power Sources With Lithium Electrode, Krasnoyarsk, 1983 (in Russian).

[9] M.V. Koudriachova, N.M. Harrison, S.W. de Leeuw, Phys. Rev. B 65, 235423 -1 (2002).

[10] S.I. Chernukhin, S.A. Kirilov, T.V. Lesnichnaya, V.D. Prysyazhny, Bull. Kharkiv National University 648, 242 (2005) (in Ukrainian).

[11] A.V. Churikov, V.A. Zobenkova, K.I. Pridatko, Russ. J. Electrochem. 40, 63 (2004).

[12] R.D. Fpostolova, N.N. Shapa, E.M. Shembel, B.I. Melnikov, Russ. J. Appl. Chem. 75, 428 (2002) (in Russian).

[13] B.I. Melnikov, A.V. Solonukha, N.N. Shapa, Voprosy Chimii I Chimicheskoy Technologii 3, 19 (2000) (in Russian).

[14] I.F. Myronyuk, B.K. Ostafiychuk, I.I. Grygorchak, R.V. Ilnytskyy, V.L. Chelyadyn, V.O. Kotsubynsky, Nanosystems Nanomaterials Nanotechnology 5, 579 (2007) (in Ukrainian).

[15] B.Ya. Venhryn, I.I. Grygorchak, Yu.O. Kulyk, S.I. Mudry, R.Ya. Shvets, Phys. Chem. Sol. State 8 , 418 (2007) (in Ukrainian).

[16] I.I. Grigorchak, I.V. Mintyansky, Z.D. Kovalyuk, P.I. Savytsky, in: Materials of Ist Conf. on Lithium Accumalators, Interbat, Kyiv 1997, p. 129.

[17] P.V. Zukowski, J. Partyka, P. Wengierek, Yu. Shostak, Yu. Sidorenko, A. Rodzik, Semiconductors 34, 1124 (2000).

[18] A.E. Kozhanov, A.V. Nikorich, L.I. Ryabova, D.R. Khokhlov, Semiconductors 40, 1021 (2006).

[19] A.G. Thompson, Phys. $B+C$ 99B, 100 (1980).

[20] I.F. Mironyuk, V.V. Lobanov, B.K. Ostafiychuk, I.I. Grigorchak, R.V. Ilnytskyy, Phys. Chem. Solid State 2, 493 (2001) (in Ukrainian).

[21] I.F. Mironyuk, B.K. Ostafiychuk, I.I. Grygorchak, R.V. Ilnytskyy, V.L. Chelyadyn, V.O. Kotsubynsky, Nanosystems Nanomaterials Nanotechnologies 5, 579 (2007) (in Ukrainian). 